\title{
Strategies to promote healthier food purchases: a pilot supermarket intervention study
}

\author{
Cliona Ni Mhurchu ${ }^{1, *}$, Tony Blakely ${ }^{2}$, Joanne Wall' ${ }^{1}$, Anthony Rodgers' ${ }^{1}$, Yannan Jiang ${ }^{1}$ \\ and Jenny Wilton ${ }^{2}$ \\ ${ }^{1}$ Clinical Trials Research Unit, School of Population Health, University of Auckland, Private Bag 92019, Auckland, \\ New Zealand: 'Department of Public Health, Wellington School of Medicine \& Health Sciences, University of Otago, \\ New Zealand
}

Submitted 14 December 2005: Accepted 24 May 2006: First published online 5 March 2007

\begin{abstract}
Objective: To pilot the design and methodology for a large randomised controlled trial (RCT) of two interventions to promote healthier food purchasing: culturally appropriate nutrition education and price discounts.

Design: A 12-week, single-blind, pilot RCT. Effects on food purchases were measured using individualised electronic shopping data ('Shop 'N Go' system). Partial data were also collected on food expenditure at other (non-supermarket) retail outlets.

Setting: A supermarket in Wellington, New Zealand.

Participants: Eligible customers were those who were the main household shoppers, shopped mainly at the participating store, and were registered to use the Shop 'N Go system. Ninety-seven supermarket customers ( $72 \%$ women; age $40 \pm 9.6$ years, mean \pm standard deviation) were randomised to one of four intervention groups: price discounts, nutrition education, a combination of price discounts and nutrition education, or control (no intervention).

Results: There was a 98\% follow-up rate of participants, with $85 \%$ of all reported supermarket purchases being captured via the electronic data collection system. The pilot did, however, demonstrate difficulty recruiting Maori, Pacific and low-income shoppers using the electronic register and mail-out.

Conclusions: This pilot study showed that electronic sales data capture is a viable way to measure effects of study interventions on food purchases in supermarkets, and points to the feasibility of conducting a large-scale RCT to evaluate the effectiveness of price discounts and nutrition education. Recruitment strategies will, however, need to be modified for the main trial in order to ensure inclusion of all ethnic and socioeconomic groups.
\end{abstract}

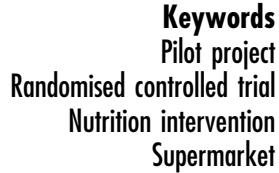

Keywords controlled trial Supermarket
The impact of nutrition on health is considerable. Across developed regions globally, nutrition-related risk factors are among the leading causes of the burden of disease ${ }^{1}$. Forty per cent of deaths in New Zealand (11 000 each year) have been attributed to the joint effects of high blood pressure, high cholesterol levels, obesity, and inadequate fruit and vegetable intake ${ }^{2}$. Together, these nutritionrelated risk factors account for $70 \%$ or more of New Zealand's stroke and heart disease mortality and more than $80 \%$ of diabetes deaths ${ }^{2}$. However, small changes in the distribution of these risk factors across the whole population could have a major beneficial impact on population health within a decade ${ }^{3-5}$.

In New Zealand, significant ethnic disparities exist for nutrition-related causes of death, in particular ischaemic heart disease, stroke and colorectal cancer ${ }^{6,7}$, and $47 \%$ of deaths among Maori (indigenous New Zealanders, comprising $15 \%$ of the population) are attributable to nutrition-related risk factors compared with 39\% among non-Maori ${ }^{8}$. Maori also have, on average, higher levels of blood pressure, cholesterol and obesity compared with non-Maori, while their consumption of fruit and vegetables is lower ${ }^{9}$. Among Pacific people in New Zealand (6.5\% of the population), substantially more Pacific adults are overweight or obese compared with their total population counterparts and a similar pattern is seen in Pacific children, whose rates of obesity are three times the national average for New Zealand children ${ }^{10}$. Socioeconomic position also has an impact on the affordability of food and access to healthy food may be limited in lowincome households ${ }^{11,12}$. Such ethnic and socio-economic inequalities in health make it imperative that nutrition research in New Zealand is designed to maximise participation and opportunity for health gain among Maori, Pacific and people from lower socio-economic groups. Therefore, inclusion of equal numbers of 
Pilot interventions to promote healthier food purchasing

participants from the main ethnic and socio-economic groups in intervention trials is important to determine the effectiveness of interventions among key population groups. Studies without sufficient statistical power to evaluate the effectiveness of interventions among Maori and Pacific people risk identifying interventions that work only for the majority population and therefore may actually increase health disparities.

The creation of supportive environments that help people to make healthy food choices is an important underlying principle in promoting healthy nutrition. Most food expenditure in New Zealand takes place in supermarkets $^{13}$, which therefore have considerable potential for environmental interventions because of their significant capacity to influence the food purchases of a large section of the population. However, to date this potential has not been fully realised. In a review of nutrition environmental interventions on point-of-purchase behaviour Seymour et al. concluded that grocery store interventions were less effective than interventions in other environments ${ }^{14}$. The major limitation of supermarket intervention studies to date has been poor outcome measures such as aggregate store sales data or dietary assessment questionnaires, but recent technological advances now make it possible to collect individualised electronic supermarket data, enabling precise measurement of changes in food purchases. A system of hand-held barcode scanning terminals that allows registered customers to scan each item they select from the supermarket shelf before putting it in their trolley ('Shop 'N Go' system) has recently been introduced into some supermarkets in New Zealand. Use of the barcode scanner, in conjunction with a personalised scannable card, allows collection of individualised electronic data on all food items purchased by a cardholder (Fig. 1).

The Supermarket Healthy Options Project (SHOP) pilot study was conducted to test the feasibility of conducting a large randomised controlled trial (RCT) of the effects of price discounts and nutrition education on supermarket food purchases using electronic data capture. Specific research questions for the pilot study included:

1. Is electronic supermarket data a feasible method of measuring the effect of study interventions on food purchases?

2. Is electronic food purchase data a valid measure of household shopping habits?

3. Is it possible to recruit adequate numbers of Maori, Pacific and low-income shoppers using an electronic register of customers and mail-out?

\section{Methods}

A 12-week single-blind RCT was conducted at a supermarket store in Wellington, New Zealand, between April

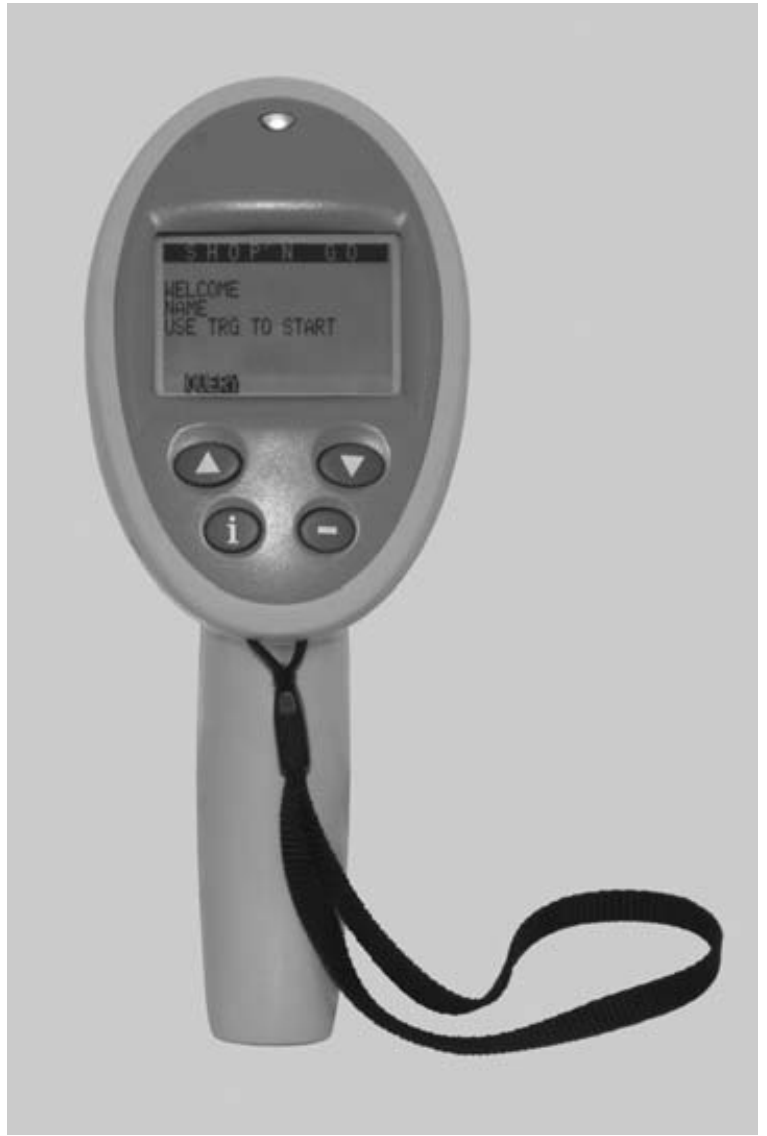

Fig. 1 Hand-held barcode scanner (Shop 'N Go system)

and July 2005. The study protocol and related documents were approved by the Wellington Regional Ethics Committee.

\section{Study participants/recruitment}

A key objective of the pilot study was to measure potential recruitment rates and numbers for the main trial. In particular, it was aimed to recruit approximately equal numbers of Maori, Pacific, and non-Maori, non-Pacific shoppers if possible. Study participants were recruited using an electronic database of customers registered to use the Shop 'N Go system. Anonymous address data for all Shop 'N Go customers (52 000 registered customers across five Wellington supermarket stores in January 2005) were initially geographically coded into mesh-blocks (census administrative areas of about 100 people) in order to identify customers living in areas known to have high proportions of Maori, Pacific or low-income residents. Preferential sampling was then used to sample customers who were eligible to participate in the pilot (Table 1) from the preferred mesh-blocks. When all customers within preferred mesh-blocks had been selected, the remainder of the sample was made up of a random selection of customers who also met the study eligibility criteria. The supermarket cooperative linked the anonymous address data to customer personal details and mailed letters to all 
Table 1 Study inclusion and exclusion criteria

Customers were eligible for inclusion in the trial if they:

- Were aged 18 years or older

- Were the main household shopper

- Shopped regularly at the participating supermarket store (i.e. shopped twice a month on average and spent no less than \$NZ 200 per month)

- Had 12 weeks of existing baseline shopping data on Shop ' $N$ Go (to serve as baseline data)

- Bought at least two-thirds of their household fruit and vegetable purchases from the supermarket

Customers were excluded if:

- They did not plan to shop at the participating supermarket store during the study intervention period

- They had taken part in previous focus groups relating to the SHOP study

SHOP - Supermarket Healthy Options Project.

selected customers inviting them to participate in the pilot study. Interested customers were asked to either telephone the local study centre or return a pre-paid card expressing interest in being contacted. Study participants were enrolled between 1 March and 1 April 2005. All participants provided written informed consent.

\section{Randomisation and interventions}

Following informed consent and baseline data collection, study participants were randomised to one of four intervention groups: price discounts, nutrition education, a combination of price discounts and nutrition education, or control (no intervention). Randomisation stratified by self-reported ethnicity (Maori, Pacific, and non-Maori, non-Pacific) was carried out using a central web-based electronic randomisation service.

The study interventions focused on promoting purchase of fruit and vegetables. Customers randomised to price discounts received an automatic $12.5 \%$ price reduction (equivalent to having the Goods and Services Tax removed) on all eligible fruit and vegetables when they presented their Shop 'N Go card at the checkout during the study intervention period. Items eligible for price discounts included fresh, frozen, dried and canned fruit and vegetables, and fruit juices comprising 100\% fruit juice. Starchy vegetables (potato, kumara, taro, etc.), pulses, sweetened fruit juices or drinks, and fruit canned in syrup were ineligible. Customers randomised to the education intervention received regular mail-outs of culturally appropriate printed nutrition education materials. Education materials were assessed and selected based on the needs of the target populations. There were no existing resources appropriate to adult Maori that specifically promoted increased consumption of fruit and vegetables so a new resource for Maori was developed. Existing education materials were used for both Pacific and non-Maori, non-Pacific populations. Materials were mailed to participants at regular intervals over the 12 -week pilot study intervention period and were supplied in the participant's preferred language(s) where available.

\section{Data collection}

At baseline, self-reported data were collected from participants on their ethnicity, education, occupation, income, household composition, shopping habits, and stage of dietary change. To measure baseline food purchase data we used 12 weeks of retrospective electronic shopping data (November 2004-January 2005). Throughout the 12-week study intervention period (April-July 2005) electronic data were collected on all purchases made at the participating supermarket. These data were merged with the main study database and coded into non-food-related purchases, food purchases, fruit and vegetables, and discounted fruit and vegetables. Data were also available on transaction dates, product descriptions, volumes sold, and price. In order to validate electronic data capture as a means of measuring household food purchases, all study participants were invited to participate in a sub-study designed to estimate the proportion of food expenditure undertaken using the Shop 'N Go system compared with food expenditure at all other retail outlets. A sample of 20 customers was selected from all those who consented and asked to complete two 7-day food expenditure diaries. The dates of the two weeks of diary completion were randomly allocated and spanned the full 12 -week intervention period. During data collection periods, participants were asked to record all food expenditure undertaken at any retail outlet and to supply till receipts where available.

\section{Statistical analysis}

No attempt was made to evaluate the effect of the study interventions on food purchase behaviour because the pilot did not have adequate statistical power to do so. However, electronic food purchase data were used to evaluate the seasonal patterns of food purchases and to compare the study participants with supermarket customers in general. For participants in the sub-study, average weekly food expenditure using the Shop 'N Go system over the intervention period was assessed while average weekly food expenditure at other food retail outlets was assessed using food expenditure diaries, enabling estimation of the proportion of total food purchases made using Shop 'N Go versus expenditure in other food retail outlets. All analyses were carried out using SAS 9.1 (SAS Institute Inc.).

\section{Results}

\section{Recruitment and participant characteristics}

Of the 116 supermarket customers who registered interest in participating in the study, 19 withdrew or were excluded prior to randomisation (Fig. 2). Non-randomised individuals were similar to study participants in terms of age, sex, ethnicity and education (data not shown). In total, 97 individuals were randomised: 24 received price discounts, 23 received nutrition education, 24 received a 


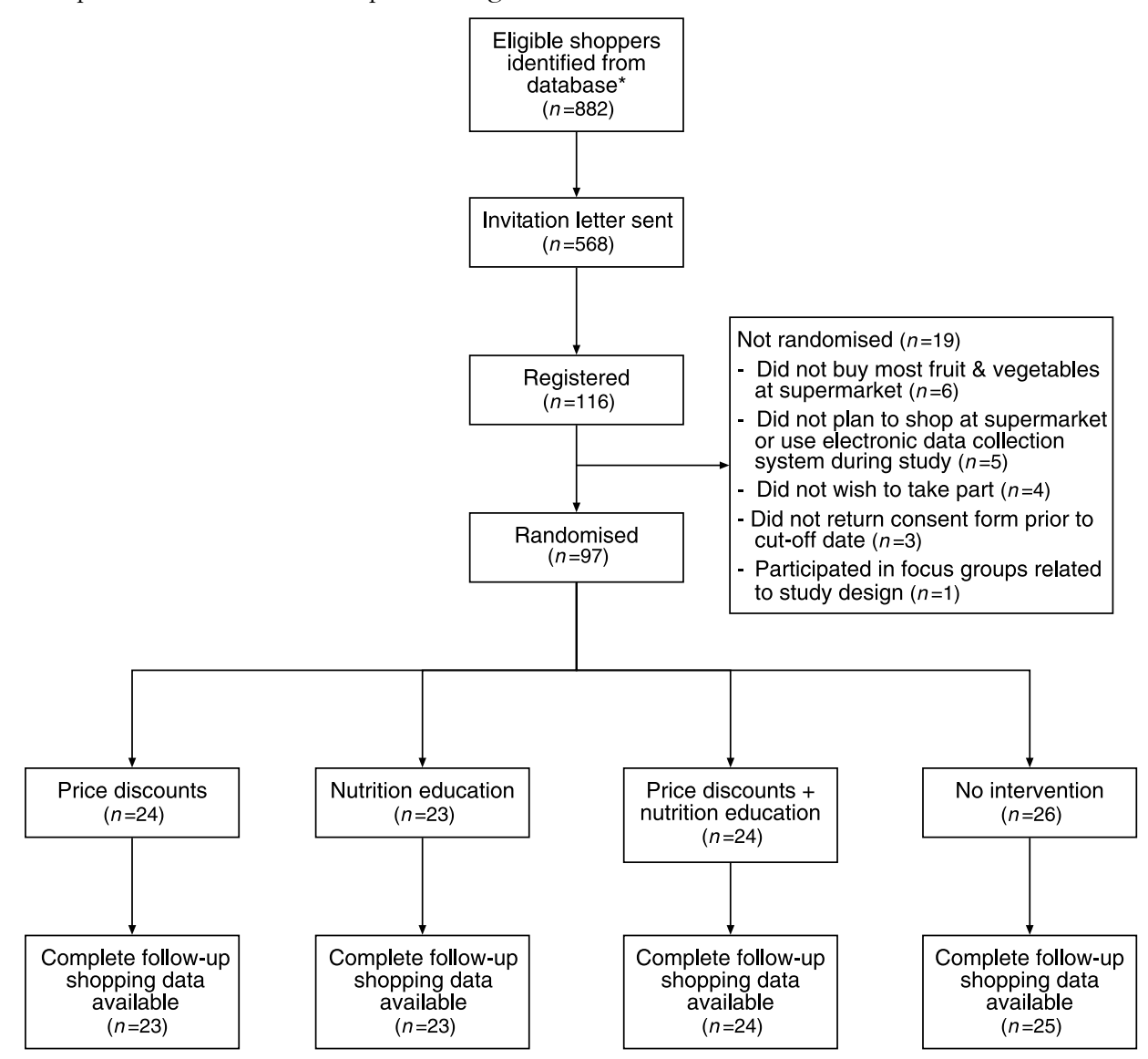

Fig. 2 Flow chart of participant recruitment and progress through the trial. "Eligible shoppers were: aged 18 years and older; shopped twice a month on average and spent no less than \$NZ 200 per month; and had 12 weeks of existing Shop 'N Go data

combination of price discounts and nutrition education, and 26 received no intervention. Follow-up shopping data for the intervention period were available for 95 of the 97 study participants (98\%). Data were unavailable for two participants: one who discontinued shopping at the supermarket following randomisation and one who did not scan the card when shopping. There were no significant differences between the baseline characteristics of participants in each intervention group (Table 2). On average, study participants were 40 years of age and $72 \%$ were women. The majority were New Zealand Europeans with only $7 \%$ describing themselves as being of Maori ethnicity and $2 \%$ as Pacific. Most (61\%) had a university or other third-level qualification and an annual mean household income exceeding \$NZ 50000 (72\%). The weekly quantity of fruit and vegetables purchased by participants during the study baseline period was $10.2 \pm 4.0 \mathrm{~kg}$ (mean \pm standard deviation).

\section{Electronic data capture}

Electronic food purchase data for 882 supermarket customers who met the study inclusion criteria (Table 1) were initially examined for a 12-month retrospective shopping period (February 2004-January 2005). The data showed a strong seasonal variation in fruit and vegetable purchases, with greater quantities being purchased in summer (December-February) than in winter (June-August) (Fig. 3). Comparison of the average quantity of fruit and vegetables purchased by study participants during the 12-month retrospective period with that purchased by all other eligible customers ( $n=785$ ) showed that study participants bought significantly greater quantities of fruit and vegetables (Fig. 3). The seasonal variation observed (highest in summer and lowest in winter) was consistent, however, between study participants and non-participants.

\section{Electronic supermarket data as a measure of overall bousebold food purchases}

The food expenditure sub-study indicated that the majority of food expenditure by study participants $(66 \%$ total food expenditure) was undertaken at the participating Pak 'N Save supermarket with most (51\% total food expenditure) being captured on Shop 'N Go (Table 3). The remainder of food expenditure was at other supermarkets (13\%) or retail outlets (20\%). Participants provided till receipts for $42.5 \%$ of all reported purchases. Where till receipts were available comparison of reported totals with the receipts indicated that there were errors in approximately one-third (35\%) of reported totals. Common errors 
Table 2 Baseline characteristics of study participants

\begin{tabular}{|c|c|c|c|c|}
\hline Characteristic & $\begin{array}{l}\text { Price discounts } \\
\quad(n=24)\end{array}$ & $\begin{array}{l}\text { Nutrition education } \\
\quad(n=23)\end{array}$ & $\begin{array}{l}\text { Discounts + education } \\
\quad(n=24)\end{array}$ & $\begin{array}{l}\text { Control } \\
(n=26)\end{array}$ \\
\hline Age (years), mean \pm SD & $39 \pm 7.3$ & $39 \pm 9.0$ & $41 \pm 8.9$ & $41 \pm 12.5$ \\
\hline \multicolumn{5}{|l|}{ Gender, $n(\%)$} \\
\hline Men & $8(33.3)$ & $5(21.7)$ & $8(33.3)$ & $6(23.1)$ \\
\hline Women & $16(66.7)$ & $18(78.3)$ & $16(66.7)$ & $20(76.9)$ \\
\hline \multicolumn{5}{|l|}{ Ethnicity, $n(\%)$} \\
\hline New Zealand European & $17(70.8)$ & $19(82.6)$ & $21(87.5)$ & $21(80.8)$ \\
\hline Maori & $1(4.2)$ & $1(4.4)$ & $2(8.3)$ & $3(11.5)$ \\
\hline Pacific & $1(4.2)$ & - & $1(4.2)$ & - \\
\hline Other & $5(20.8)$ & $3(13.0)$ & - & $2(7.7)$ \\
\hline \multicolumn{5}{|l|}{ Highest level of education, $n(\%)$} \\
\hline None & $1(4.2)$ & $1(4.4)$ & $2(8.3)$ & $2(7.7)$ \\
\hline Secondary school & 7 (29.2) & $11(47.8)$ & $3(12.5)$ & 7 (26.9) \\
\hline University/third level & $16(66.7)$ & $10(43.5)$ & $18(75.0)$ & $15(57.7)$ \\
\hline Other & - & $1(4.4)$ & $1(4.2)$ & $2(7.7)$ \\
\hline \multicolumn{5}{|c|}{ Annual pre-tax household income (\$NZ), $n(\%)$} \\
\hline$<20000$ & $1(4.2)$ & - & - & $2(7.7)$ \\
\hline $20001-50000$ & $5(20.8)$ & $2(8.7)$ & $5(20.8)$ & $7(26.9)$ \\
\hline$>50001$ & $16(66.7)$ & $19(82.6)$ & $18(75.0)$ & $16(61.5)$ \\
\hline Declined to answer & $2(8.3)$ & $2(8.7)$ & $1(4.2)$ & $1(3.9)$ \\
\hline \multicolumn{5}{|l|}{ Household composition, mean \pm SD } \\
\hline Number of adults & $2.1 \pm 0.6$ & $2.3 \pm 0.8$ & $2.2 \pm 0.8$ & $2.2 \pm 0.7$ \\
\hline Number of children & $1.8 \pm 1.5$ & $1.6 \pm 1.0$ & $1.5 \pm 1.3$ & $1.8 \pm 1.7$ \\
\hline \multicolumn{5}{|l|}{ Frequency of takeaway purchases, $n(\%)$} \\
\hline Less than once a week & $6(25)$ & $6(26.1)$ & 7 (29.2) & $11(42.3)$ \\
\hline Once a week & $17(70.8)$ & $16(69.6)$ & $15(62.5)$ & $14(53.9)$ \\
\hline 2-4 times per week & $1(4.2)$ & $1(4.3)$ & $2(8.3)$ & $1(3.8)$ \\
\hline \multicolumn{5}{|l|}{ Frequency of eating out, $n(\%)$} \\
\hline Less than once a week & $14(58.2)$ & $15(65.2)$ & 8 (33.3) & $16(61.5)$ \\
\hline Once a week & $10(41.7)$ & $6(26.1)$ & $13(54.2)$ & $9(34.6)$ \\
\hline 2-4 times per week & - & $2(8.7)$ & $2(8.3)$ & $1(3.8)$ \\
\hline Missing & _- & - & $1(4.2)$ & - \\
\hline \multicolumn{5}{|c|}{ Weekly household expenditure on food (\$NZ), $n(\%)$} \\
\hline$<100$ & $2(8.4)$ & - & $4(16.7)$ & $6(23.1)$ \\
\hline $100-150$ & 9 (37.5) & $7(30.4)$ & 8 (33.3) & $6(23.1)$ \\
\hline$>150$ & $13(54.1)$ & $16(69.6)$ & $11(45.8)$ & $14(53.8)$ \\
\hline Missing & - & - & $1(4.2)$ & - \\
\hline $\begin{array}{l}\text { Weekly quantity of fruit and vegetables } \\
\text { purchased }(\mathrm{kg}) \text {, mean } \pm \mathrm{SD}\end{array}$ & $10.4 \pm 3.0$ & $12.0 \pm 5.1$ & $9.2 \pm 2.9$ & $9.4 \pm 4.3$ \\
\hline
\end{tabular}

SD - standard deviation.

were inclusion of non-food items or pet food in reported totals and failure to take into account discounts applied.

\section{Discussion}

This pilot study demonstrated the feasibility of conducting a large-scale RCT to evaluate strategies to promote purchase of healthy foods from supermarkets. In particular, the pilot showed that collection of electronic supermarket data is a viable means to evaluate food purchases and test the effectiveness of nutrition interventions and promotions. Extremely high follow-up rates were achieved using this method and the system captured the vast majority of reported purchases made at the participating supermarket.

Accurate assessment of diet is a prerequisite for assessing the impact of nutrition interventions. There are many methods of dietary assessment but most are associated with problems including reliance on self-report, recall bias and measurement error, and are labour-intensive for both participants and researchers ${ }^{15}$.
More streamlined electronic methods of dietary assessment are therefore being developed. Supermarket till receipts have been evaluated as an index of the fat and energy content of the diet of supermarket shoppers and a strong association was seen between estimates of intakes of fat and energy using 4-day food diaries and 28 days of till receipts ${ }^{16}$. Other studies have also used till receipts to characterise food purchases ${ }^{17,18}$. However, the use of receipts still involves burden on the part of the participant (to collect the receipts) and study staff (to code and enter the food purchase data). A recent UK study used a smart card payment system to track the food choices of almost 1000 children in a school cafeteria $^{19-21}$. Technological advances make it possible to utilise a similar system to evaluate supermarket food purchases.

Our SHOP pilot study demonstrated that it is feasible to use individualised electronic supermarket data as an objective measure of the effect of interventions on food purchases. This method could be utilised to measure nutrition interventions in any supermarket that has the 
Pilot interventions to promote healthier food purchasing

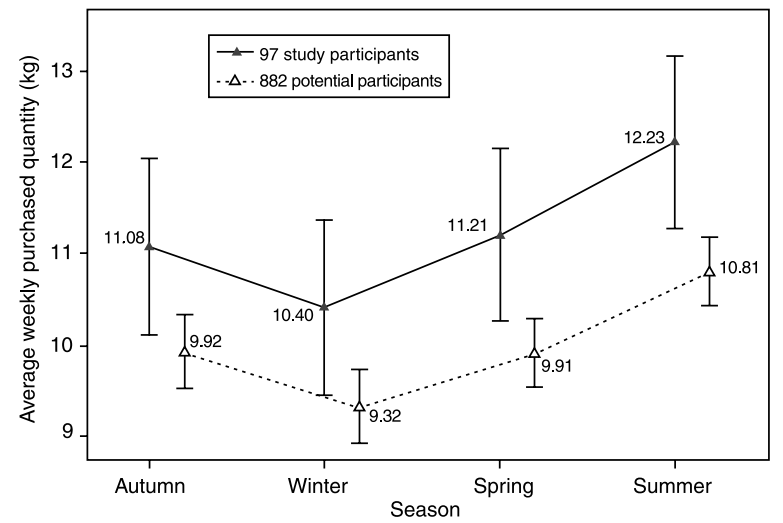

Fig. 3 Seasonal fruit and vegetable purchases

means to capture individualised food purchases, e.g. those with customer loyalty card schemes, and has many potential advantages including the 'real-time' capture of supermarket purchases, thus enabling personalised or tailored feedback to customers. However, limitations include the fact that it is a measure of food purchases rather than food consumption and, more specifically, it is a measure of household supermarket food purchases. Furthermore, it does not provide information on what happens to the food once it is purchased; i.e. who actually consumes it (members of the household or guests), how it is cooked, how much is wasted, etc. Nevertheless, since supermarket interventions necessarily focus on influencing food purchases rather than consumption, the main focus of any outcome measure should also be food purchases.

In order to capture reliable data on what people buy in supermarkets the electronic data collection system must be used consistently by the study participants. This involves remembering to take their card to the supermarket each time they shop and also to swipe it at the checkout. The pilot indicated that approximately $15 \%$ of

Table 3 Food expenditure sub-study $(n=20)$

\begin{tabular}{lcc}
\hline Shopping location & $\begin{array}{c}\text { Mean weekly } \\
\text { expenditure (\$NZ) }\end{array}$ & $\begin{array}{c}\text { Proportion } \\
(\%)\end{array}$ \\
\hline $\begin{array}{l}\text { Participating supermarket } \\
\text { using Shop 'N Go }\end{array}$ & 124.23 & 51 \\
$\begin{array}{l}\text { Participating supermarket not } \\
\quad \text { using Shop 'N Go }\end{array}$ & 36.10 & 15 \\
Other supermarket chain & 29.35 & 12 \\
Restaurant or workplace canteen & 19.78 & 8 \\
Takeaway bar or shop & 15.83 & 6 \\
Butchery or bakery & 5.79 & 2 \\
Dairy or service station & 3.07 & 1 \\
Other supermarket store in the & 2.49 & 1 \\
$\quad$ same chain & & \\
Market & 1.78 & 1 \\
Fruit \& vegetable shop & 0.49 & 0 \\
Delicatessen & 0.43 & 0 \\
Snack machine & 0.41 & 0 \\
Superette & 0.29 & 0 \\
Other outlet & 4.39 & 2 \\
\hline
\end{tabular}

supermarket food purchases at the participating store were not captured using the Shop 'N Go system, mainly because customers forgot their cards or the system was not operational when they shopped. Despite these limitations, the pilot showed that electronic supermarket data capture the large majority (85\%) of what people buy in supermarkets, making it a reliable, cost-effective tool to assess the impact of supermarket interventions or programmes. It also avoids the errors we found were associated with using till receipts as an index of food purchases (missing data and mathematical errors).

Another important study finding was that we were unsuccessful in our bid to enrol a range of ethnic and socio-economic groups, which suggests that mail-outs from the Shop 'N Go customer database were not effective recruitment strategies for Maori, Pacific and low-income shoppers. This finding is borne out by additional consultation with Maori and Pacific groups (six focus group discussions were held with Maori (2), Pacific (2), and non-Maori, non-Pacific (2) shoppers during the study implementation) and co-investigators. A clear message from this consultation was the need for face-to-face recruitment for Maori and Pacific shoppers. Important changes will therefore be made to the recruitment strategy for the main trial, including use of more community-based and 'shop floor' (supermarket-based) recruitment. In order to test this proposed change to the study design, the study team has since conducted a small survey at the participating supermarket store, approaching 43 Maori and Pacific shoppers to ascertain their interest and willingness to be involved in the main study. Less than half (47\%) were already users of the electronic Shop 'N Go system, and most of the remainder were not aware of how it worked. Once the study and the Shop 'N Go system were explained to the participants, however, all but six stated they would be prepared to change their shopping practice to use Shop 'N Go in order to be involved in the proposed study. Whilst indicative only, this survey does suggest that a 'shop floor' recruitment strategy for Maori and Pacific people in the main study is likely to be effective. Since it appears that Maori, Pacific and low-income shoppers currently have a low uptake of the Shop 'N Go technology, the main study will need to take this into account by enrolling and training study participants to use the system where necessary and including a run-in period to allow new users to adapt to the system before baseline shopping data are collected.

Fifty-nine per cent of annual household food expenditure in New Zealand is in supermarkets and, at \$NZ 6.6 billion per year, this is the largest category of food expenditure by far ${ }^{13}$. Supermarket interventions have the advantage of being a cost-effective and efficient way of accessing, evaluating and intervening with a wide crosssection of the population (entire households/families) and of promoting partnership between health sector/research and the food industry. A recent review of supermarket 
interventions found that studies to date have produced conflicting results ${ }^{14}$. Eight of the 10 studies reviewed used information strategies only to promote targeted food items, while two used additional strategies of availability, access or incentives as well as information. Five of the 10 studies reported no increase in sales of targeted food items while the remaining five studies reported increased sales for up to half of targeted items. However, in all cases, outcomes were assessed using either aggregate store sales data (\% total sales) or some form of dietary assessment, neither of which is an ideal measure.

In conclusion, the SHOP pilot study successfully evaluated the study design and methodology for a largescale RCT of strategies to promote healthier supermarket food purchases. In particular, the pilot showed that electronic supermarket data capture is a feasible method of measuring effects of nutrition interventions on food purchases in supermarkets. Recruitment strategies will, however, need to be modified in order to ensure inclusion of all ethnic and socio-economic groups in the proposed main study. The proposed RCT is strategically important: it is an intervention study conducted in collaboration with the food industry, an approach that will be central to nutrition research and public health action in the coming decades, and it has been designed in partnership with Maori and Pacific organisations and co-investigators to ensure inclusion of population groups at greatest risk of nutrition-related disease in New Zealand.

\section{Acknowledgements}

Sources of funding: This study was funded primarily by the Health Research Council of New Zealand and the National Heart Foundation of New Zealand. The Cancer Society of New Zealand also provided some financial support.

Conflict of interest declaration: There is no conflict of interest.

Authorship responsibilities: All named authors have made a substantial contribution to the published manuscript as follows: C.N.M. - design and conduct of research, interpretation of data, preparation and approval of manuscript; T.B. - design and conduct of research, interpretation of data, approval of manuscript; J.W. design and conduct of research, interpretation of data, approval of manuscript; A.R. - design and conduct of research, interpretation of data, approval of manuscript; Y.J. - statistical analysis and interpretation of data, approval of manuscript; J.W. - conduct of research, interpretation of data, approval of manuscript.

Acknowledgements: We are grateful to staff at the Clinical Trials Research Unit involved in programming (Alex Bormans, Colleen $\mathrm{Ng}$ ), data management (Gery Smith, Terry Holloway, Amanda Milne) and administrative support (Mary Cosson, Deanne Douglas, Sheila Fisher); to staff at the Wellington School of Medicine who assisted with the conduct of the study focus groups and pilot (Losa
Moata'ane, Jo-Ani Robinson, Louise Signal, Jo Peace); to co-investigators at Te Hotu Manawa Maori who provided advice on the design and conduct of the study from a Maori perspective (Laurie Wharemate, Leonie Matoe); to co-investigators at the Pacific Islands Heartbeat Programme who provided advice on the design and conduct of the study from a Pacific perspective (Iutita Rusk, Mafi Funaki-Tahifote); and to staff at Foodstuffs Wellington who assisted with mail-outs, electronic data system merging, and implementing price discounts (Mike Kotlyar, Daniel Pickering, Malcolm Batchelor, Alistair Garvie, Dean Galt). We are particularly grateful for the contribution of the 97 study participants.

\section{References}

1 Ezzati MLA, Rodgers A, Vander Hoorn S, Murray CJL, and the Comparative Risk Assessment Collaborative Group. Selected major risk factors and global and regional burden of disease. Lancet 2002; 360: 1347-60.

2 Stefanogiannis N, Lawes C, Turley M, Tobias M, Vander Hoorn S, Ni Mhurchu C, et al. Nutrition and the burden of disease in New Zealand: 1997-2011. Public Health Nutrition 2005; 8: 395-401.

3 Ni Mhurchu C, Turley M, Stefanogiannis N, Lawes C, Rodgers A, Vander Hoorn S, et al. Mortality attributable to higherthan-optimal body mass index in New Zealand. Public Health Nutrition 2005; 8: 402-8.

4 Turley M, Tobias M, Lawes C, Stefanogiannis N, Vander Hoorn S, Ni Mhurchu C, et al. Cardiovascular mortality attributable to high blood cholesterol in New Zealand. Australian and New Zealand Journal of Public Health 2006; 30: $252-7$

5 Tobias M, Turley M, Stefanogiannis N, Vander Hoorn S, Lawes C, Ni Mhurchu C, et al. Vegetable and fruit intake and mortality from chronic disease in New Zealand. Australian and New Zealand Journal of Public Health 2006; 30: 26-31.

6 Blakely T. The New Zealand Census-Mortality Study: Socioeconomic Inequalities and Adult Mortality 1991-94. Wellington: Ministry of Health, 2002.

7 Blakely T, Tobias M, Robson B, Ajwani S, Bonne M, Woodward A. Widening ethnic mortality disparities in New Zealand 1981-99. Social Science \& Medicine 2005; 61: $2233-51$

8 Lawes CMM, Stefanogiannis N, Tobias M, Paki Paki N, Ni Mhurchu C, Turley M, et al. Ethnic disparities in nutritionrelated mortality in New Zealand: 1997-2011. New Zealand Medical Journal 2006; 119: U2122.

9 Russell DG, Parnell WR, Wilson NC, Faed J, Ferguson E, Herbison P, et al. NZ Food: NZ People. Key Results of the 1997 National Nutrition Survey. Wellington: Ministry of Health, 1999.

10 Ministry of Health. The Health of Pacific Peoples. Wellington: Ministry of Health, 2005.

11 Kirkpatrick S, Tarasuk V. The relationship between low income and household food expenditure patterns in Canada. Public Health Nutrition 2003; 6: 589-97.

12 Drewnowski A, Specter SE. Poverty and obesity: the role of energy density and energy costs. American Journal of Clinical Nutrition 2004; 79: 6-16.

13 Statistics New Zealand. 2003/04 Household Economic Survey. Wellington: Statistics New Zealand, 2004.

14 Seymour JD, Yaroch AL, Serdula MK, Blanck HM, Khan LK. Impact of nutrition environmental interventions on point-ofpurchase behavior in adults: a review. Preventive Medicine 2004; 39: S108-36. 
15 Margetts BM, Nelson M. Design Concepts in Nutritional Epidemiology, 2nd ed. Oxford: Oxford University Press, 1998.

16 Ransley JK, Donnelly JK, Khara TN, Botham H, Arnot H, Greenwood DC, et al. The use of supermarket till receipts to determine the fat and energy intakes in a UK population. Public Health Nutrition 2001; 4: 1279-86.

17 Winett RA, Anderson ES, Bickley PG, Walberg-Rankin J, Moore JF, Leahy M, et al. Nutrition for a lifetime system: a multimedia system for altering food supermarket shoppers' purchases to meet nutritional guidelines. Computers in Human Behavior 1997; 13: 371-92.

18 Walberg Rankin J, Winett RA, Anderson ES, Bickley PG, Moore JF, Leahy M, et al. Food purchase patterns at the supermarket and their relationship to family characteristics. Journal of Nutrition Education and Behavior 1998; 30 $81-8$.
19 Lambert N, Plumb J, Looise B, Johnson IT, Harvey I, Wheeler $\mathrm{C}$, et al. Using smart card technology to monitor the eating habits of children in a school cafeteria: 1. Developing and validating the methodology. Journal of Human Nutrition and Dietetics 2005; 18: 243-54.

20 Lambert N, Plumb J, Looise B, Johnson IT, Harvey I, Wheeler $\mathrm{C}$, et al. Using smart card technology to monitor the eating habits of children in a school cafeteria: 2 . The nutrient contents of all meals chosen by a group of 8- to 11-year-old boys over 78 days. Journal of Human Nutrition and Dietetics 2005; 18: 255-65.

21 Lambert N, Plumb J, Looise B, Johnson IT, Harvey I, Wheeler $\mathrm{C}$, et al. Using smart card technology to monitor the eating habits of children in a school cafeteria: 3. The nutritional significance of beverage and dessert choices. Journal of Human Nutrition and Dietetics 2005; 18: 271-9. 